\title{
Bacon's Apples: A Case Study in Baconian Experimentation
}

\section{Dana Jalobeanu ${ }^{\text {* }}$}

\begin{abstract}
This paper investigates a specific case of Baconian experimentation, that is, a series of controlled experimental trials he undertook to study the processes of maturation and putrefaction of apples when they were placed under very different circumstances and conditions. The results of these trials were repeatedly used by Francis Bacon in his writings to illustrate the motions of spirits enclosed in matter. In this paper, I reconstruct some of Bacon's experiments with apples from his recurrent references, as found in the Historia vitae et mortis, De vijs mortis, Novum organum and Sylva Sylvarum. I argue that they shed important light on three problematic aspects in Baconian scholarship. Firstly, they offer a paradigmatic situation in which we can explore Bacon's creative and critical handling of sources. Secondly, they show Bacon at work as an experimenter who carefully and accurately observed, recorded and imagined interesting experimental set-ups and variations of experimental parameters, while displaying an interest in experimental methodology and the limits of experimental procedure. Finally, Bacon's apples are very good examples of the multiple uses and functions experiments play in his natural and experimental histories.
\end{abstract}

\section{$1 \quad$ Introduction}

References to experiments and trials made with apples and other fruit are numerous in Bacon's works, particularly in the posthumous Sylva Sylvarum (1627). They appear in no less than 37 of his so-called 'experiments' distributed in eight of the ten parts ('centuries') of the work. They refer to the study of various phenomena and processes, such as maturation and putrefaction, preservation, conservation and induration. In these experiments, apples and other fruits are placed in different mediums; sometimes, they are enclosed in earthen jars, in boxes, or bottles, sometimes buried in the ground, placed in 'conservatories of snow' or immersed in water, honey, or vinegar, etc. In other cases, apples are simply placed in hay, straw, chalk or sand, or said to be coated in wax, hung in smoke, or immersed in quicksilver. In each case, the 'experiment' signifies the investigation of the effects produced on fruit by external conditions and the lapse of time. In some, this is supplemented by a comparative evaluation of the results of several such 'experiments'. In one of the most detailed such experimental accounts, formulated in Century 4 of Sylva Sylvarum, the procedure is described in full:

\footnotetext{
* Research for this chapter has been carried out with the support of the ERC Starting Grant 241125 MOM. My thanks to Guido Giglioni and James Lancaster for their useful suggestions and comments on this chapter.
} 
There were taken apples, and laid in straw; in hay; in flour; in chalk; in lime; covered over with onions; covered over with crabs; closed up in wax; shut in a box, \&c. There was also an apple hanged up in smoke (Bacon 1857-1874, II, 446).

The lapse of time in this case is one month. In the list of experiments that follow, Bacon gives a quite detailed description of what happens to each of the apples 'after a month's space'. We learn that the apple covered in wax was 'as green and fresh as at the first putting in', that it maintained its 'first freshness and moisture', while the others were more matured, not only in comparison with it, but also in comparison with 'another Apple, of the same kind, that lay of it selfe' (i.e., not enclosed or buried in any of the substances indicated) (Bacon 1857-1874, II, 447). By contrast, 'the apple hanged in the smoke, turned like an old mellow apple, wrinkled, dried, soft, sweet, mellow within', while the apple kept in straw looked matured, but not as much as those kept in hay, etc. (Bacon 1857-1874, II, 447). Other experiments throughout the Sylva Sylvarum make reference to apples kept for a month in quicksilver, snow, water, vinegar and honey. A different, but related line of experimentation involves burying apples under earth for varying amounts of time, such as, for example, Experiment 377:

An orange, lemon and apple, wrapt in a linen cloth, being buried for a forthnight's space four foot deep within the earth, though it were in a moist place and a rainy time, yet come forth no ways mouldy or rotten, but were become a little harder than they were; otherwise fresh in their colour; but their juice somewhat flatted. But with the burial of a fortnight more they become putrefied (Bacon 1857-1874, II, 467).

Mark, again, the quite thorough description of the results: the appearance and taste of the fruits after one month in the ground, and the variation of these results after doubling the time elapsed.

In other examples, apples are first placed in sealed containers before being subsequently buried in the ground, placed in deep wells, or covered in ice or 'conservatories of snow', etc. In this case, the 'body is left to itself for a good while, armed and defended in the meantime against any external force' (Bacon 2004, 434-435). ${ }^{1}$ As a result, changes in the appearance of the fruit after a given time are said to be the sole effects of particular 'motions within' it (motus intestini). These are the motions of the 'spirits' enclosed in matter. Of course, for Bacon spirits are at the origin of all changes and alterations; they are the agents of motion and the motive power behind everything that occurs in nature. They produce processes called concoction, maturation and putrefaction. In terms of spirits, however, such processes are reduced to motions, such as a 'calling forth of the spirits of the body outward', a 'spreading' of the spirits 'more smoothly' (what is commonly known as maturation), or the action through which the spirit is 'digesting in

\footnotetext{
${ }^{1}$ This is one of the seven modes of operation (modi operandi) presented in the Novum organum under the name 'multi-purpose instances'. The multi-purpose instances are said to 'promote practice'(Bacon 2004, 445). They also formalize the order of operating upon bodies in the experimental process. The fourth mode of operation is called a 'lapse of time (per moram)'. Bacon provides the following definition for it: 'Lapse of time is what I call it when any body is left to itself for a good while, armed and defended in the meantime against any external force. For when extraneous and extrinsic motions stop, then do the ones working within show and perfect themselves' (Bacon 2004, 435).
} 
some degree the grosser parts' of the enclosing body (part of what is commonly known as putrefaction) (Bacon 1857-1874, II, 446). In fact, these processes are phases of a continuous motion of alteration: a motion which begins with assimilation (when the apple is still on its branch) and continues towards putrefaction (when the spirits, after spreading evenly inside the apple and 'digesting' some of its matter, tend to fly out and, in this attempt to escape, produce disordered motions and 'swellings' inside the fruit). Apples are a recurrent example in Bacon's attempts to illustrate these processes, and references to experiments with apples are to be found in De vijs mortis (c. 1611-1619), in the Historia vitae et mortis (1623), and even among the prerogative instances of the Novum organum (1620).

Take, for example, the apple coated in wax from the experiment discussed above. In the Sylva Sylvarum it is used to compare the effect of external agents upon a controlled process of maturation. By isolating the apple in wax, by 'entrapping' its spirit, one can delay the process of maturation. Therefore, after a month, the apple is 'as green and fresh as the first putting in', because 'all exclusion of open air (which is ever predatory) maintained the body in his first freshness and moisture'. On the other hand, in De vijs mortis the results of the same wax coating are described after a different lapse of time, when the fruits have already begun to putrefy. As a result, the enclosed apples become 'moist and as if they were macerated and suffused with a watery sweat' (Bacon 1996, 309). This quite thorough description of the 'beginnings of putrefaction' seems to suggest more than just chance observation. It indicates repeated experimentation, attention to detail and, perhaps, even the development of a methodology specially designed for the study of natural processes that are extremely complex and difficult. Did Bacon really perform such experiments with apples, though? Repeated experiments recorded in his writings seem to suggest a positive answer. The problem, however, is more complicated, because many of the experiments described by Bacon come not from actual practice, but from his readings. This is the case, for instance, of a paragraph from the Historia vitae et mortis, which seems to summarize the results of a newly discovered technique, namely, the isolation of fruits in such a way that 'predatory air' cannot reach them:

Fruits such as pomegranates, lemons, apples, pears, and the like, and flowers such as the rose and lily keep for a long time when sealed in earthenware pots; yet the ambient air still interferes by carrying and insinuating its inequalities through the sides of the pot, as is obvious in heat and cold, so that it is best if the pots be well sealed to bury them below the grounds as well. No less effective is to put them if not underground but under water, provided that the water be out of the light as well, and in domestic cisterns; but if you put them under water it is better to use glass rather than earthenware pots (Bacon 2007, 167). ${ }^{2}$

This is indeed a summary of many observations and repeated trials; only it is one whose development is not to be found in Bacon's writings, but in Book 4 of Giambattista della Porta's

\footnotetext{
${ }^{2}$ Versions of the same can be found in the Sylva Sylvarum, Experiments 343, 379, and 624-629.
} 
Magia naturalis (1558), Chapter 7 and $8 .^{3}$ There, Della Porta (1535?-1615) discusses comparatively the various ways to preserve apples and other fruits in earthenware pots buried under ground, placed in dust, chalk, or in water cisterns. Alternative means of preservation discussed, sometimes completed with descriptions of experimental set-ups and methodology, include using snow and ice, wine, honey, quicksilver and amber. Meanwhile, in describing these experiments, Della Porta himself refers rather to books than to actual practice. Many of his recipes for preservation and delaying putrefaction come from a classical tradition: the tradition of husbandry.

The critical and creative way in which Della Porta handled this classical tradition in his Magia naturalis has been only partially investigated (Orsi 2005). In Bacon's case, even a limited investigation is still missing. This is partly due to the long lasting influence of the verdict formulated more than a century ago by James Spedding, Robert L. Ellis and Douglas D. Heath, the nineteenth-century editors of Bacon's works. In his introduction to Sylva Sylvarum, Spedding claimed that 'Porta's Natural magic supplied Bacon with almost all he says of the changes which may be produced in fruits and other vegetable products by peculiar modes of cultivation' (Bacon 1857-1874, II, 328). Spedding treated Bacon's borrowings from Della Porta as simple 'transcriptions' of recipes and experiments, sometimes deceptively attributed to 'one of the ancients'. It is only recently that scholars have questioned Spedding verdict and begun a more thorough investigation of this process of borrowing and 'transcribing'. And although Bacon's reading of Della Porta has attracted in the past couple of years a certain amount of attention, much more remains to be done before one can have an accurate picture of Bacon's complex and sophisticated ways of using Magia naturalis as a sourcebook of experiments. ${ }^{5}$

My purpose in this paper is to show that Bacon's 'borrowings' from Della Porta and his handling of recipes and experiments is both historically complex and philosophically interesting. In the first instance, I show that Bacon used Della Porta's Magia naturalis, in a liberal and creative manner, as a source-book of experiments. I will also attempt to show that Della Porta was not the only source of experiments and recipes when it comes to Bacon's own experiments

\footnotetext{
${ }^{3}$ Della Porta's Natural Magic was a sixteenth century bestseller, and remained extremely popular throughout the seventeenth century. The first edition, published in Naples in 1558, was almost immediately translated into Italian (1560), French (1565), Dutch (1566) and German (1612). The first edition comprised only four books. Della Porta published a second, augmented edition in twenty books (Naples, 1589), including in it a substantial amount of his own experiments with plants and fruits, together with experimental endeavours dealing with optics and magnetism. In what follows, I will refer to this augmented edition. The second edition of Della Porta's Natural Magic was also translated into Italian (1611), French (1606), English (1658) and German (1680). I will refer to this second edition of Della Porta's Natural Magic. On the differences between the first and second edition see Balbiani 2001. Finally, I will refer to the Latin edition published in Frankfurt in 1591 and to the English translation (anonymous) published in 1658 (Porta 1591, 1658). Unless otherwise stated, all quotations in English come from Della Porta 1658, and the Latin quotations come from Della Porta 1591.

${ }^{4}$ Although Graham Rees has contested this verdict as early as 1981, it is only fairly recently, and due to recent interest devoted to techniques of reading, writing and the tradition of common-places that Bacon's own methods of 'research' have become focus of more thorough investigations. On Bacon's methods of common places see Vine 2008, Vine 2011, Yeo 2014, Stewart and Knight 2012. See also Rees 1981. On Bacon's handling of classical sources, more generally, see Giglioni 2012, Jalobeanu 2008 and 2012.

${ }^{5}$ For a more general assessment of Bacon's reading of Della Porta see Rusu 2013. Recent studies have discussed several 'experimental' aspects of Della Porta's Magia naturalis. See Borelli 2014, Jalobeanu and Pastorino 2014.
} 
with apples. Other ancient and modern sources found their way into Bacon's notebooks, 'calendars of problems', and eventually into his published writings. In particular, I will discuss the striking similarities between Bacon's handling of experiments with fruits and Hugh Platt's study of the same subject. My general claim in this paper is that such a contextual reconstruction of Bacon's apple-experiments is vital for an understanding of two related problems. Firstly, it offers important insights into the critical and creative way in which Bacon handled his sources, insights that can bring further clarification to the much-discussed relation between reading, experimenting and recording, on the one hand, and developing and imagining new experiments, on the other. Secondly, by understanding how Bacon used books of husbandry, natural history and natural magic as sources for his experimental activities, we can begin to understand how Baconian experimentation developed: from the first stages of selection, critical reading and testing of received recipes to the more creative stages of articulating experiments, constructing experimental 'series' of trials and formulating hypotheses.

The first two sections of this paper are devoted to tracing the sources of Bacon's experiments with apples, as well as a discussion of the critical and creative ways he had read and interpreted them. In the third section, I will provide arguments for a more general claim, i.e, that, despite borrowing primary materials and sometimes fully developed technologies, Bacon did do some of the experiments he recorded in his writings. Finally, the last section of my paper is dedicated to a discussion of the various uses to which Bacon put his apples; experiments with apples are used to illustrate the motions of the spirits enclosed in matter, but also, and equally, they are used in the classification and definition of natural processes (such as maturation and putrefaction). They also provide a simplified laboratory model for the study of more complex problems, such as the prolongation of life.

\section{Dealing with Sources: Commonplaces, Criticism and Creativity}

The Sylva Sylvarum contains a good number of recipes for the preservation of fruits, though sometimes these are simply abbreviated transcriptions of ancient and modern sources. Such, for example, are Experiments 627, 628 and 655, which deal with how to preserve grapes in such a way that they will 'continue fresh all winter long'. ${ }^{6}$ One suggestion is to hang them 'cluster by cluster in the roof of a warm room'; another emphasizes that 'it is reported' that the preservation of the stalk 'helpeth to preserve the grape; especially if the stalk be put into the pitch of elder, the elder not touching the fruit'. Another recipe reads:

Take grapes and hang them in an empty vessel well stopped; and set the vessel not in a cellar, but in some dry place; and it is said they will last long. But it is reported by some they

\footnotetext{
${ }^{6}$ These examples belong to a particular class of experiments in the Sylva sylvarum called 'promiscuous experiments'. See Bacon 1857-1874, II, 542.
} 
will keep better in a vessel half full of wine, so that the grapes touch not the wine (Bacon 1857-1874, II, 535). ${ }^{7}$

Some of these recipes are formulated as reports received on credit, while others are written in more tentative terms, as if implying that the reader is called to try for herself, verifying in this way the received report. In yet other cases, Bacon gives a list of recipes, written in terms which seem to suggest a previously attempted trial, such as the following list:

The conservation of fruit would be also tried in vessels filled with sand, or with powder of chalk; or in meal and flour; or in dust of oak wood; or in mill (Bacon 1857-1874, II, 534).

Similar recipes are recorded in the Historia vitae et mortis, where a list consisting of sand, chalk, meal and flour is supplemented with other substances, such as wax and plaster, resin, snow and ice, salt water, oil, wine, various 'liquors', honey, spirit of wine and quicksilver (Bacon 2007, 169). The language in which such recipes are recorded in the Historia vitae et mortis and Sylva Sylvarum differs substantially: where the latter merely gives the recipe and suggests a trial, the former offers results and comparative evaluations of the recipes, for instance:

Bodies hung in wine, oil, or lees keep for a long time, but much longer in honey, and spirit of wine, but some say that they keep longest of all in quicksilver (Bacon 2007, 169).

In the Sylva Sylvarum, moreover, we can find a further generalization of the same list of recipes. Situated in the middle of a theoretical discussion about conservation and putrefaction is recorded: 'bodies in shining amber, in quicksilver, in balms... in wax, in honey, in gums and (it may be) in conservatories of snow, \&c. are preserved very long' (Bacon 1857-1874, II, 589).

Did Bacon do such experiments? Did he actually place apples and other fruits under different conditions, comparing the results, as some of the recorded experiments seem to suggest? Or was he simply systematizing in these 'experiments' received recipes and observations recorded in earlier books? The answer is not straightforward. On the one hand, none of the recipes recorded in the Sylva Sylvarum or Historia vitae e mortis is 'new': all the conditions, substances and suggested trials recorded by Bacon can be found in other ancient and modern authors. On the other hand, these recipes do not come from a single tradition. Some belong to the more traditional discipline of husbandry, ${ }^{8}$ while others can be found in books of

\footnotetext{
${ }^{7}$ Compare this passage with the following one from Pliny, Historia naturalis, XV, 18 (in Philemon Holland's translation): 'And more particularly, for Grape bunches they would be gathered with a foot or heele from the old hard wood... then be hung up within a great new earthen vessel well pitched; with the head or lid thereof thoroughly stopped and plastered up close, to exclude all aire... Some againe there be who keepe Grapes together with their braunch, after the same manner in plaster; but so, as both ends of the said braunch, after the same sticke in the head of the sea-Onion Squilla: and others let Grape-clusters hang within hogheads and pipes having wine in them: but so, as the grapes touch not the wine in any case' (Pliny and Holland 1601, 441).

${ }^{8}$ Scholars tend to distinguish sharply between the Roman tradition of husbandry as preserved in books on de re rustica and the more modern tradition of natural history (histories of plants, herbals). The first is a discipline midway between 'politics' (in the Aristotelian sense) and agriculture. In the sixteenth century, this discipline of husbandry became very popular in Italy and France (and subsequently in the rest of Europe). The ancient sources of | this tradition were Marcus Porcius Cato's De agricultura (c. 160 BC), Marcus Terentius Varro's, _De re rustica (c.
} 
natural magic or books of secrets (where they are often called 'experiments). ${ }^{9}$ Bacon has clearly read both, for he commends 'collections made of agriculture' (Bacon 1857-1874, III, 332), and, although he is highly critical of 'books of fabulous experiments and secrets' (Bacon 1857-1874, III, 330), he nevertheless recommends the assembling of two large 'calendars' of 'inventions' and 'useful experiments'. 10

An example of this approach is Bacon's so-called 'promiscuous experiments' (624 to 629 from the Sylva Sylvarum), all of which deal with the conservation of fruits. The first gives a traditional recipe for keeping quinces in a syrup of honey, as well as possible variations of the same recipes in which one replaces the honey with a syrup of sugar or sugared wine. The second provides a list of good preservatives and fruit-lofts; vessels 'filled with fine sand, or with powder of chalk', 'meal and flour', 'dust of oak wood' and 'mill'. The third experiment explains how to pick fruits so that they might last long: for instance, it is suggested that they be picked just before they are fully ripe, in dry weather, and at noon, 'when wind bloweth south; and when the moon is under the earth, and in decrease' (Bacon 1857-1874, II, 534-535). The fourth offers recipes for the preservation of grapes hung 'in a dry place', or in a vessel half-filled with wine. The fifth specifies the need to isolate the stalk of the fruits by putting it into elder pith, while the sixth mentions the traditional recipe of keeping fruits in bottles 'let down into wells under water'. What Bacon is thus offering in this string of experiments is an interesting selection of recipes for the preservation of fruits.

One of Bacon's possible sources for these experiments is Pliny's Historia naturalis (c. 77-79 AD). In Book 15, Chapter 18, he gave a list of recipes which was itself an abbreviated discussion of a subject that had already been treated extensively by such authors as Cato, Varro and Columella, a subject traditionally belonging to the field of husbandry (oeconomia). The chapter makes reference to quinces 'boiled or soaked in honey', to pomegranates or apples kept in 'large jars of sand', in flour or mill, and to grapes stored in earthenware vessels 'carefully smeared with a coating of pitch' and sunk 'into wells or cisterns'. It also contains the suggestion that one thrust the stalk of apples 'into elder pith'. Pliny also gives two (conflicting) recipes for

\footnotetext{
37 BC) and Lucius Iunius Moderatus Columella's, De re rustica (60-65 AD). To these were later added compilations, such as a fifth-century book on res rusticae by Palladius and the later Geoponica (tenth century AD). By the mid-sixteenth century, these sources often appeared bound together under the common name De re rustica. By the mid-sixteenth century, many books in the vernacular had been added to this ancient tradition. Part translation, part adaptation of ancient traditions, these books became quite popular, translated and adjusted to 'local' contexts. Such, for example, is Charles Estienne's compilation from Columella, 'adapted' to French agricultural practices and further translated and adapted into English by Richard Surflet (see Estienne and Liébault 1570; Estienne and Surflet 1600; Orsi 2005). Although the situation is more complex than this when it comes to the flourishing literature on agriculture and gardening, nevertheless, for the kind of recipes and experiments concerning the preservation of fruits this division is useful. They belong mainly to a particular chapter in books on husbandry; a chapter dedicated to preserving and increasing 'household stuff' in a farm. On the reception of the classical tradition of husbandry, see Fussell 1969 and Bushnell 2003.

${ }^{9}$ On the relation between Della Porta and the tradition of 'secrets', see Eamon 1984; Eamon 1994; Ruscelli [Alexis of Piedmont] 1984; Orsi 2005.

${ }^{10}$ In this instance, by 'usefulness' Bacon understands 'productivity', that is, experiments which prove to be conducive to new inventions and experiments. He explicitly mentions modern 'technologies' in this chapter, as in the recipe for the artificial freezing of water. See Bacon 1857-1874, IV, 369 and Bacon 1857-1874, III, 362-3.
} 
how to pick the fruits in such a way that they may last a long time. In the first, apples are to be picked after the autumn equinox, 'not before the sixteenth day of the moon nor later than the twenty eight day of the moon', on a dry day, early in the morning 'an hour after sunrise'. The second recommends to pick the fruit 'before it is completely ripe', towards noon on a dry day, when the wind blows from the south, and 'when the moon is waning' and 'below the horizon'. ${ }^{\text {' }}$ Of the two, Bacon selects the second, but leaves out some of the other recipes mentioned by Pliny in the same chapter, such as to pack fruit in flocks of wool, to enclose apples and pears in small individual earthenware pots and to submerge them under water, or to use 'potters clay' to cover grapes and dry them in the sun before hanging them in a dry place.

In conclusion, Bacon's string of experiments reads as a selection of recipes borrowed from Pliny and the ancient tradition of husbandry, but with two notable additions: the proposal to replace honey with sugar or sweetened syrups, and the replacement of earthenware pots with glass bottles. Both are extensions of the ancient recipes for the preservation of fruits, using 'modern' technologies (glass) and substances (sugar). The first is common in literature on husbandry, natural magic and books of secrets at the end of the sixteenth century. ${ }^{12}$ The preservation of fruits in vials of glass is described at length in Book 4 of Della Porta's Magia naturalis, in the context of a general discussion in which ancient recipes on how to preserve fruits are closely evaluated. After mentioning various recipes for creating artificial 'fruit-safes', that is, devices for hermetically isolating the fruits from the surrounding air, ${ }^{13}$ and after discussing various ways to seal and plaster such vessels, Della Porta claims to have repeatedly shown that fruits and flowers 'shut up in vessels of glass' and 'drowned in Cisterns, or ditches, or some place underneath the ground' last the longest without putrefaction (Della Porta 1658, 121). ${ }^{14}$

Fruits are to be laid up in vials of glass, as we shewed before: and when the pipe or neck of the glass is stopt close up, then they are to be drowned in cisterns, and they will last good for certain whole years. Likewise, flowers are to be closed up in a vessel that is somewhat long, and the neck of it must be stopt up [per Hermetis sigillum, in the original], as we viewed before, and then they must be cast into the water: for by this means they may be kept fresh

\footnotetext{
${ }^{11}$ Pliny, Historia naturalis, XV, xviii, 62: 'E proximis quidam altius curam repetunt, deputarique statim poma ac vites ad hunc usum praecipiunt decrescente luna, post horam diei tertiam, caelo sereno aut siccis ventis. Similiter deligi et ex locis siccis et ante perfectam maturitatem, addito ut luna infra terram sit'. See Pliny 1949-1962, IV, 331.

${ }^{12}$ On the more general interest in producing glass cheap enough to be used for greenhouses and gardening, see Thick 2010, 57ff.

${ }^{13}$ Oropothecas is a term introduced by Varro to designate a place for storing fruits. It becomes for Della Porta a technological device which isolates fruit from the damages produced by heat and variations in the air (see Della Porta 1589, 175). The English translator renders this term with 'fruit-safes' or 'artificial fruit-safes'. For a more general discussion in Della Porta, see his work Villae, Chapter 28, entitled 'De oropothecis' (Della Porta 1592, 5657).

${ }^{14}$ See also Della Porta 1658, 126: 'For I have oft-times observed it, being seriously imployed in these affairs, that if the air be uniform, and without alteration, the fruits and flowers that have been shut up in vessels of glass, have lasted long without any putrefaction: but when once they felt any alteration in the air, presently they began to putrefie. For this cause are those vessels to be drowned in Cistern, or ditches, or some place underneath the ground, that so the variable alterations of the air may not be felt by the fruit'.
} 
for a long time. I have also put new wine into an earthen vessel that hath been glazed within, and have laid it in the water with a weight upon it to keep it down; and a year after, I found it in the same taste and goodness, as when I put it into the vessel. By the like device as this is, we may preserve things that are shut up, even for ever (Della Porta 1658, 128). ${ }^{15}$

In this way, Della Porta goes one step further than traditional recipes for preserving fruits over the winter, and offers a general 'technology' for preservation: sealed glass bottles placed under water in deep wells protect the enclosed objects from the variations of the surrounding air and thus delay putrefaction. ${ }^{16}$ The procedure is no longer directed solely towards the preservation of fruits; it is extended to flowers, meat, wine and other bodies. Also, it is no longer strictly concerned with how to preserve bodies for the purpose of simple utility: what these recipes suggest are more general ways of delaying, or even preventing putrefaction. They lead to the general conclusion that sealing up perishable materials in durable substances can permanently prevent putrefaction. ${ }^{17}$ Della Porta's favorite example is amber: sealed in amber, bodies are preserved forever. Consequently, Chapter 8 of Book 4 of Magia naturalis ends with a recipe for 'how to make amber soft' in order to use it as a universal preservative. Della Porta also mentions other 'universal' preservatives: quicksilver, ${ }^{18}$ distilled spirit of wine ${ }^{19}$ and the more general (and also more mysterious) effect of cold in preserving bodies and delaying putrefaction. ${ }^{20}$ For each of these 'universal' preservatives, Della Porta claims he has made 'experiments' and 'trials'. ${ }^{21}$

\footnotetext{
${ }^{15}$ See also Della Porta 1589, 85. 'Fructus, uti diximus, in vitreas phialas conditos, ac vitrariorum fornaci, vel tubulo lumini clausos sub cisternis mergimus, et ad annos incorruptos servamus. Eodem modo clausos flores in oblongo vase, et collo ut diximus occluso, scilicet per Hermetis sigillum, ut dicunt, et sub aquis mersos, diu, multumque recentes asservavimus. Item mustum in vas sigiluum vitreatum clausum, et pondere sub acquis demersum, ad anuum, ut posuimus invenimus'.

${ }^{16}$ The recipe is listed under the very general title: 'How all things that are shut up, may be preserved for many years' (Della Porta 1658, 128).

${ }^{17}$ Della Porta 1658, 130-131: 'things that are shut up, even for ever, if we wrap them up in some commixtion of other things, so that the air may not pierce them through; but especially, if the commixtion it self be such, as is not subject to putrefaction'.

${ }^{18}$ Under the title 'Quicksilver will preserve all things from putretude', Della Porta provides a general recipe for placing fruits in vessels and 'cast[ing] quicksilver upon them', in order to 'preserve them long and well' (Della Porta $1658,140)$.

${ }^{19}$ Della Porta claims that all things can be preserved in distilled wine, which is 'free from all putrefaction whatsoever: wherefore all things that are drenched in this kind of liquor, if the vessel be carefully closed up, must needs last unputrefied even for a hole age, nay for all eternity' (Della Porta 1658, 134).

${ }^{20}$ The chapter on fruit-safes ends with a paragraph on the preserving powers of cold: 'I have seen flesh and fish preserved from putrefaction, for a whole moneth together in very cold places, without any other art at all besides the coldness of the place. In rooms that are made under the ground, and very cold, where there cometh neither heat, nor any Southerly winde, but that they are continually cold and dry, almost every thing may be preserved without putrefaction. [In subterraneis locis,et frigidissimis, ubi omnis calor, et austrinus ventus excludes est, ubi perpetua siccitas et frigiditas est, Omnia imputrida, asservantur]'. The passage continues with two observations: first, that "in a certain monastery" near Naples, human cadavers (hominum cadavera) were preserved 'for many years together', and second, that fruits placed in 'pits of snow' have survived the winter completely unchanged. From this, Della Porta concludes that 'there is nothing better and more available for the preservation of any thing, then is the dryness and the coldness of such places as they are laid up in, to be kept. [In summa nil praesentabilius ad rerum conservationem, quam loci siccitas, vel frigiditas valet]' (Della Porta 1658, 116-7; Della Porta 1591, 178).

${ }_{21}$ As Eamon has shown, in the sixteenth century the terms 'secrets' and 'experiments' were sometimes used interchangeably to denote a recipe or a formula that had actually been put to the test. In these trials there is always a
} 
Book 4 of Magia naturalis is a curious mixture of traditional recipes and new experiments, of mere collections of 'trials' and serious reflections on the limits and methods of experimentation. At first sight, it contains the same kind of miscellaneous materials about 'husbandry' that we find in Book 12 of Columella's De re rustica (60-65 AD). ${ }^{22}$ It deals with how to preserve the products of farming, how to increase 'household stuffe', how to ensure the good administration and the good life of the farmer and his household. ${ }^{23}$ By the end of the sixteenth century, this had become a widespread literary model for the organization of various books on husbandry. ${ }^{24}$ Many of these books, however, differ significantly from the ancient tradition of res rustica, as does Della Porta's book on 'increasing the household stuffe'.

There are at least three important ways in which Della Porta's ideas about the preservation of things differ from the classical tradition. First of all, his interest is not only confined to finding the best recipe for preserving fruits for the winter, but relates to a more general attempt to delay putrefaction 'for many years', or even 'forever'. ${ }^{25}$ His evaluative and comparative discussion of various received recipes and methods of husbandry is clearly directed towards discovering the best devices to ensure long-term preservation of fruits, flowers, liquids, meat and corpses. ${ }^{26}$ Some traditional methods are subject to close scrutiny and criticism, and new methods are proposed to replace the traditional recipes of Varro, Columella and Palladius. ${ }^{27}$ Therefore, Book 4 of Magia naturalis is more than a traditional compilation of recipes and, in this respect, differs substantially from all other traditional books on husbandry, natural history

mixture of bookish sources and new inventions. The 'experimenters' sometimes collaborate along the way in collecting recipes. See Eamon and Paheau 1984, 333; Eamon 1985, 484.

${ }^{22}$ Book XII of Columella's De res rustica deals with the duties and “offices" of the farmer's wife. They extend from taking care of the household stuff, provisions and furniture, to ministering to the health of the household. The preservation and conservation of the products of the farm forms the most important part of the chapter. Recipes are offered for picking herbs, fruits and vegetables, storing them, making preserves, oil, wine, and distilled drinks, etc.SeeColumella 1745, XII, 500ff.

${ }^{23}$ Book 4 of Magia naturalis also contains materials developed more fully in his Villae. As Orsi has shown, Della Porta used the results of his investigations in Villae to expand (to the point of rewriting) the first edition of the Magia naturalis (see Della Porta 1592 and Orsi 2005).

${ }^{24}$ See, for example, the additions and changes made to the organization of the translation and adaptation of Book 12 of Columella's De re rustica by Charles Estienne, Jean Liebault and Richard Surflet. In Estiene, Agriculture (1570), the contributions of the farmer's wife are redefined. She is in charge of the health of the household and of the breeding of cattle and fowls. The breeding of fowls extends also to pheasants, doves and peacocks. Meanwhile, the parts about preserving fruits, making wine and olive oil are redistributed in the chapters dedicated to gardens. In Richard Surflet's edition of Estienne's Agriculture or the Countrie Farme, the medical contributions of the farmer's wife, for example, are widely extended. So are the sections on the medicinal properties of herbs, fruits and vegetables cultivated on the property(Estienne and Liébault 1570; Estienne and Surflet 1600).

${ }^{25}$ More generally, Della Porta's interest is in producing marvelous objects (meraviglia); objects that will create wonder and testify the power of the magician (see Orsi 2005; Balbiani 2001). It is also worth noting, however, Della Porta's critical discussion of ancient sources of husbandry. In Book 4 he constantly engages in comparisons of ancient recipes, sometimes specifically rejecting one in favor of another. See, for example, Della Porta $1658,112$. ${ }^{26}$ One of the recurrent topics of Book 4 is the preservation of human bodies in the cold, in the snow and in honey. Della Porta also gives a recipe for mummification (Della Porta 1658, 140-141).

${ }^{27}$ Almost every chapter of Book 4 begins with a selection of ancient recipes followed by what Della Porta claims to be his own trials and recipes. Sometimes this is also announced at the beginning of the chapter. For example: 'We have shewed before, that, if we would preserve fruit long, we must keep away both heat and moisture from them; both which qualities are found in the air. Wherefore we will first set down the devices of Antiquity in this behalf, and then our own device and experiments' (Della Porta 1658, 123. See also Della Porta 1658, 112, 114, 120). 
and agriculture. Della Porta offers a selection of the best methods and a comparative and quite critical discussion of ancient sources. In some cases, he clearly goes a step further and discusses the limits of various experiments. In a characteristic manner, Della Porta writes, for example, of which fruits can and which fruits cannot be preserved in honey, thereby demonstrating that honey is not a universal 'preservative', as it was traditionally assumed. ${ }^{28}$ By contrast, amber, quicksilver and spirit of wine are better and more universal preservatives. This also relates to the third significant difference between Della Porta's treatment of preservation and the way the subject is handled in the classical tradition. Although the emphasis of Della Porta's natural magic is on the production of marvelous and miraculous objects, such as mummies, flies, vipers and other animals enclosed in amber, and flowers conserved in quicksilver, it is equally clear that the production of natural magic technologies relies on a certain amount of theoretical support. In the case of conservation, preservation and the devising of things that last 'forever', the technology of creating 'artificial fruit-safes' is based upon a causal theory about putrefaction. There are two major causes that produce putrefaction, and they both act in the same way: through the air. But more precisely, through what Della Porta calls the 'inequalities of the air', ${ }^{29}$ that is, changes in the levels of heat and cold together with varying (and sometimes conflicting) influence of celestial bodies. ${ }^{30}$ In order to prevent putrefaction, the practitioner in natural magic has to isolate the body from all external influences. This isolation includes two components: hermetical sealing (excluding the direct action of the air upon the body) and thermal isolation (in order to prevent a situation in which the body is affected by variations in the surrounding air).

Echoes of Della Porta's views on the preservation of bodies abound in Bacon's natural histories. Incidentally, the manuscript of the Sylva Sylvarum explicitly quotes 'Porta. Fol. 195' as a source for a trial named 'Leven to last a yeare'. ${ }^{31}$ However, while Della Porta's interest in leaven occurs in a chapter on making bread, Bacon is more interested in the clarification, maturation and preservation of beer. Both in the manuscript of the Sylva Sylvarum and in the published text, experiments which deal with apples are on adjacent pages with similar

\footnotetext{
${ }^{28}$ Della Porta 1658, 130: 'I have endeavoured my self in this Practise, how to keep fruits without putrefaction, and for this cause, I laid up all kinds of fruits in vessels of glass filled with honey, that so I might prove, which might be preserved longest: and I found great difference among them, some kinds lasting long and some but a little while. For, the fruits that were by their own kind, full of moisture, did attaint the honey: so that the honey begin it self attained, was not possibly able to preserve the fruit from putrefaction. Grapes, Figgs and Peaches are soon putrified by reason of their moistness; quinces, apples and pears do last longer uncorrupted; but Nutts will last green and sound a whole year together'. See also his similar discussion about the limits of other traditional recipes for the preservation of fruits, such as keeping them in wine and vinegar (Della Porta 1658, 134).

${ }^{29}$ This phrase encompasses not only variations of temperature and humidity, but also other qualities of the air, such as a certain tendency to putrefy or produce putrefaction determined by a particular astral configuration; a 'pestilence' of the air, etc. For a more extended discussion, see Della Porta 1592, 56-57.

${ }^{30}$ An elaborated discussion of the agents of putrefactions can be found in Della Porta's Villae, where the focus is less on experiments and the production of marvelous effects and more about theoretical debates over the agents and causes of putrefaction amongst the ancients (see Della Porta 1592, 51-53).

${ }^{31}$ I have used Graham Rees's transcription of Bacon's manuscript in Rees 1981. The reference is to Della Porta's 1591 edition of Magia naturalis. The recipe in the 1658 translation reads: 'If you would have leaven last you all the year, when the new wine hath boiled in the vessels, skim off the froth that boils on the top, and mingle with it Millet-meal, and work it wll together, and make morsels of it, which dry in the Sun, and lay up in a moist place; and you may take a sufficient quantity and use it for leaven' (Della Porta 1658, 142).
} 
experiments concerning bottles of beer. Folio $43^{\mathrm{r}}$ of the manuscript begins with the following list:

Beer in Lime. / Beere in Dung / Beere hanged up in Smoke. / Beere in Bran. / Beere twice a day jogged in the wheele-barrow. / Beere swung 4 times a day (Rees 1981, 405).

Bottles of beer also appear in different lists, for example on a list of 'experiments' to be tried in a conservatory of snow and on a list of 'burials'. 32

The published version of the Sylva Sylvarum records the potential results of such trials. However, they are developed in separate sets of experiments, and Bacon makes it clear that they deal with different problems. One set of experiments treats simply with methods for the preservation of beer once this is made; they can be seen as simply extended treatments of knowledge accumulated from Della Porta and various books on husbandry, dealing with a range of subjects that goes from apples and wine to beer. Another set of experiments refers to producing beer, to ways of accelerating the process of 'clarification' of new beer and its 'maturation'. This time, the conditions suggested go against traditional recommendations for good preservatives in matter of husbandry, such as dung (an agent of putrefaction), hot ambers or 'rotating' bottles to speed up the process of maturation and fermentation. Consider, for example, the following experiment:

Take bottles and swing them, or carry them in a wheel-barrow, upon rough ground, twice in a day; but then you may not fill the bottles full, but leave some air; for if the liquor come close to the stopple, it cannot play nor flower: and when you have shaken them well either way, pour the drink into another bottle, stopped close, after the usual manner; for if it stay with much air in it, the drink will pall; neither will it settle so perfectly I all the parts. Let it stand some twenty-four hours, then take it, and put it again into a bottle with air, ut supra: and thence into a bottle stopped ut supra: and so repeat the same operation for seven days. Note that in the emptying of one bottle into another, you must does it swiftly, lest the drink pall. It were good also to try in a bottle with a little air below the neck, without emptying. This instance is referred to the even distribution and refining of the spirits of motion (Bacon 1857-1874, II, 444).

Not only is this experiment not taken from Della Porta; it is also too complex and detailed to be a mere theoretical extension based upon traditional experiments in husbandry (say, experiments relating to the production and preservation of wine). It has many significant details, including quantitative directions regarding the lapse of time and the number of repetitions necessary to produce the effect. It contains methodological cautions and caveats relating to the limits of the

\footnotetext{
${ }^{32}$ For example, fol. $39^{\mathrm{r}}$ contains a list of 'Infusions or Burialls of Bodies in Earth', in which various substances are mentioned, such as eggs, wax, flowers, flesh and oyster shells. Some of the objects are marked with a star, suggesting perhaps that that particular trial was done or 'sorted out'. Marked with stars are oranges, apples and 'a bottle of beer'. The list ends with an interesting remark concerning the repetition of the suggested trials: 'Each in 3 several places' (Bacon 1996, 403).
} 
recipe and the procedures to be followed, not to mention a reference to a possible theoretical explanation. Moreover, it is clear that through these experiments involving fruit or bottles of beer Bacon intends to study similar processes under similar conditions, in this case, the fact that spirits entrapped in matter produce effects after a certain lapse of time.

What we can see in this series of experiments is the creative ways in which Bacon uses accumulated knowledge. Although he incorporates many of the traditional trials and recipes found in Pliny, Columella and Della Porta, Bacon employs them as merely 'materials for the building' of quite different 'experiments', trials and recipes. First, he makes a selection of experiments, to which he frequently appends comparative and detailed studies of the results; to these he then adds his own contribution to the initial recipe. In proceeding thus, Bacon is not very dissimilar to Della Porta, applying the same critical and creative reading. However, he might be seen as moving a step further (in the same direction), through extending the series of observations from fruits to bottles of beer.

Another characteristic way in which Bacon borrows experiments from previous authors concerns critical (and theoretical) reflections. ${ }^{33}$ For example, he clearly takes from Della Porta a list of preservatives which were very dear to the natural magic tradition, such as spirit of wine 'well rectified', quicksilver and amber. The reference is at times almost verbatim:

We see, how flies and spiders, and the like, get a sepulcher in amber, more durable than the monument, and embalming of the body of any king. And I conceive the like will be of bodies put in quicksilver. ${ }^{34}$

The same list of preservatives is detailed in 'Experiment solitary touching prohibition of putrefaction and the long conservation of bodies', which begins with a recipe for mummification (also given by Della Porta), and continues with the bold statement that 'putrefaction, which we conceive to be so natural a period of bodies, is but an accident'. The paragraph continues with a list of Della Porta's favourite preservatives:

And therefore bodies in shining amber, in quicksilver, in balmes (whereof we now speake), in wax, in honey, in gummes, and (it may be) in conservatories of snow, \&c., are preserved very long (Bacon 1857-1874, II, 598).

In the very same passage, Bacon is also openly critical of Della Porta. First of all, he does not agree with Della Porta's theory regarding the agents and causes of putrefaction. Nor does he agree with the possibility of preserving bodies forever, irrespective of their storage in amber, quicksilver, 'balms' or conservatories of snow. Quite to the contrary, Bacon clearly states that in

\footnotetext{
${ }^{33}$ For a more general discussion of Bacon's criticisms of Della Porta's experiments, recipes and "technologies" see also Rusu 2013.

${ }^{34}$ In the corresponding passage, Della Porta refers to one of Martial's Epigrams (IV, 59), where the Roman poet had described a viper enclosed in amber, which, in this way, had found a nobler and more everlasting tomb than Cleopatra herself: 'Flentibus Heliadum ramis dum vipera repit / Fluxit in obstantem succina gemma feram, /Quae dum miratur pingui se rore toneri, / Concreto riguit vincta repente gelu, /Ne tibi regali placeas, Cleopatra, sepulchro, / Vipera si tumulo nobiliore iacet' (Della Porta 1658, 128; Della Porta 1589, 85).
} 
order to be preserved in amber bodies need to be relatively small, thin and devoid of all moisture. Moist bodies will putrefy, no matter how well sealed, and the spirit enclosed in them will find a way to get out, regardless of how thick the isolating material is. For Bacon, there are two major causes of putrefaction, located respectively in the body and in its surrounding environment:

All putrefactions come chiefly from the inward spirits of the body; and partly also from the ambient body, be it aire, liquor, or whatsoever else. And this last, by two means: either by ingress of the substance of the ambient body into the body putrefied; or by excitation and solicitation of the body putrefied, and the parts thereof, by the body ambient (Bacon 18571874, II, 612).

Given these premises, Bacon concludes that, although useful, hermetic isolations and the exclusion of the surrounding air are not sufficient to delay or prevent putrefaction. ${ }^{35}$ Further difficulties have to be overcome; such as the nature of the body under investigation and its interaction with the surrounding enclosure. In part, it is a problem of scale: if leaves, small insects and other small and dry bodies might be trapped 'forever' in amber or ice, the same is not valid for fruits, flesh, corpses or any other bodies in which the spirit can move and 'make a round and circulation within themselves' (Bacon 1857-1874, II, 384). This means that practically any body large enough or so 'gross... may corrupt within itself' (Bacon 1857-1874, II, 589). ${ }^{36}$ In this case, the inner spirit will continue its workings and will try to find a way out of the closure, irrespective of how hermetic the sealing is. The third, and perhaps most important part of the problem of preservation is related to the surrounding enclosure. It involves finding bodies 'not commaterial, but merely heterogeneal towards the body that is to be preserved' (Bacon 18571874, II, 589), and for this role quicksilver is one of Bacon's favourite candidates. The manuscript of the Sylva Sylvarum contains numerous references to experiments with fruits and flowers 'hung in quicksilver', with apples 'dipped' in quicksilver or with pieces of raw flesh 'buried' in quicksilver. ${ }^{37}$ However, they are clearly not experiments for preserving things 'forever'. The time recorded in such experiments is rather short; it can be days, or weeks, but no longer than a month. Only one of these experiments is recorded in the published version:

Take a stock-gilly-flower, and tie it gently upon a stick and put them both into a stoop-glass full of quicksilver, so that the flower be covered: then lay a little weight upon the top of the glass that may keep the stick down; and look upon them after four or five days; and you

\footnotetext{
${ }^{35}$ Bacon argues that 'human working on natural bodies' is often 'much upset' by the 'common air which is all round, and thrust itself upon us, and by the rays of the heavenly bodies'. As a result, it is essential that such factors be eliminated. Under the instances of special power (Instantiaae polychrestae), he discusses the theory and 'technology' underlying the creation of these sealing devices (Bacon 2004, 418-419).

${ }^{36}$ Bacon also notes that the exclusion of air, far from preventing putrefaction, speeds up putrefaction in those bodies 'that need emission of spirits to discharge some of the superfluous moisture'. This is why clothes that are not regularly aired breed mold, or grains that stored over winter and are not regularly turned over turn moldy (Bacon 1857-1874, II, 454).

${ }^{37}$ See, for example, 'A piece of raw fles buried in Quicksilver for 9 daies, came forth fresh, and some bloud had wrought it selfe out, and lay on the outside of the Quick-silver, and about the stick that kept it downe. It was waxed a little blacker on the outside only, but not apparently hardened' (Rees 1981, 402).
} 
shall find the flower fresh, and the stalk harder and less flexible than it was. If you compare it with another flower gathered at the same time, it will be more manifest. This sheweth that bodies do preserve excellently in quicksilver; and not preserve only, but by the coldness of quicksilver indurate; for the freshness of the flower may be merely conservation; (which is the more to be observed, because the quicksilver presseth the flower;) but the stiffness of the stalk cannot be without induration, from the cold (as it seemeth) of the quicksilver (Bacon 1857-1874, II, 598).

There are clear similarities between this experiment and analogous trials conducted by contemporary practitioners of natural magic. Its expected result is clearly shared: a remarkable 'object' that will most probably create wonder. Moreover, the carnation dipped in quicksilver has unusual and unexpected properties; although looking fresh, it becomes stiff and hard. On the other hand, the way in which Bacon records experiments differs in significant ways from Della Porta's recipes for natural magical findings. It differs, firstly, in its details. The reader is instructed about what to do and receives full information about what is to be obtained after five days. Secondly, the results of the experiment are assessed by comparison with a standard case: the dipped flower is contrasted with another flower gathered at the same time, so that it is possible to gauge the level of their respective 'freshness'. Finally, Bacon points to the fact that the experiment produces not one, but two effects: though it is kept 'fresh', the flower suffers a process of 'induration' (that is to say, it becomes stiff and hard). We are even offered a causal explanation for the induration: the coldness of quicksilver.

\section{Technologies, Experimentation and the Books of Secrets}

Although his experiments recording the effects of placing flowers, fruits and flesh in quicksilver are more sophisticated and detailed than Della Porta's recipes, it would be premature to assume that the difference is due solely to the fact that Bacon performed them. In fact, many of Della Porta's recipes for preservation became common stock in the sixteenth-century literature on secrets. In the specific case of Della Porta's technology concerning the construction of' "fruitsafes', I identified at least one important follower amongst Bacon's contemporaries, namely, Sir Hugh Platt (1552-1608). Platt's book, The Jewell House of Art and Nature (1594), ${ }^{38}$ opens with a chapter entitled: 'Sundry new and artificial ways for the keeping of fruits and flowers, in their fresh hue, after they are gathered from the stalks or branches'. The chapter advocates technologies borrowed by and inspired from Della Porta, ${ }^{39}$ developed in the same creative and critical manner I have thus far attributed to Bacon. Similar techniques can also be found in

\footnotetext{
${ }^{38}$ The popularity of Hugh Platt's Jewell House in the seventeenth-century is subject to contention. While Deborah Harkness makes a case for the book's popularity, Malcolm Thick claims that by comparison with other works by Platt, Jewell House is the least popular. However, the book went through a second edition in 1653 and parts of it were published separately as pamphlets. See Harkness 2007; Thick 2010.

${ }^{39}$ For Platt's reading of Della Porta's Magia naturalis, see Mukherjee 2010 and Thick 2010.
} 
Platt's other books, for example in his widely read Floraes Paradise (1608). ${ }^{40}$ Platt openly poses as both a champion and a critic of Della Porta, whom he reprimands for using a 'cloudy and dark' language. ${ }^{41}$ All this calls for a more careful comparative examination of Platt's and Bacon's technologies of experimenting with fruit. We might inquire, for instance, whether Bacon's critical and creative borrowings were the mere result of a common technique of reading, learning and experimenting that was widely available at the time through the popular books of secrets.

As a Cambridge educated gentleman, trained at Lincoln's Inn and practicing the law, Platt is not the most likely trader of secrets. His books represent a strange mixture of scholarly pursuits and strikingly wide interests in natural history, husbandry, the mechanical arts, alchemy and natural philosophy, with a practical concern for the improvement of the land, the cultivation of new species, knowledge of ciphers and the discovery of innovative methods for distillation, germination and the prolongation of life. Platt's vast knowledge and experimental skill - but, most of all, his manner of reasoning on the basis of experiments followed by queries, further developed in new experiments and then supplemented by theoretical hypotheses, which, in turn, are tested by other experiments - are so strikingly similar to Bacon's form of experimental philosophy that Deborah Harkness has reached the conclusion that plagiarism was involved on Bacon's part. ${ }^{42}$ My purpose in this paper is not to substantiate or refute such accusations, but rather to concentrate on examining particular instances of similarity and divergence between Bacon's and Platt's experiments with fruit, plants and beer. There are numerous references in Bacon's natural historical works to the types of experiments and recipes tried or merely suggested in Platt's books. They are enough, in fact, to suggest that a careful comparative study of the two corpuses is necessary in order to establish what may in fact be another important source behind Bacon's project for a 'new' natural history. For the present purpose of this paper, however, it does not really matter whether Bacon actually read Platt and borrowed directly from his books. I take Platt's experiments and recipes as representing another way of reforming the ancient tradition of husbandry, and compare them with Bacon's similar concerns and reformulations of the same problems.

Platt offers many experiments for the preservation of fruit, flowers, wine and beer. He is interested in both the economic aspects of their preservation and the provision of theoretical explanations. He claims that his experiments and recipes are a mixed bag: 'some are but mine owne Conceits and Quaeres, and some, the reports of other mens practices'. Some are said to have failed but still be worthwhile for their 'probabilities'. Others are good to learn, in order to find out more about nature and her secrets. Platt is clearly familiar with Della Porta's 'fruitsafes'. The first chapter of The Jewell House offers, in fact, Platt's own improved versions of

\footnotetext{
${ }^{40}$ For a discussion of Platt's Florae and a discussion of Bacon's borrowings of gardening recipes from it see Rusu 2013.

${ }^{41}$ Platt 1608, A4: 'And I make no question, but that if hee [Della Porta] had knowne this part of vegetale Philosophy... he would have penned the same as a Sphinx, and rolld it up in the most cloudy and darksome speech that he could possibly have devised'.

${ }^{42}$ (Harkness 2007: 248-9) . For a more nuanced discussion of Platt's projects and outlook, see Thick 2010.
} 
'fruit-safes' with a critical discussion of Della Porta. His recipes for the preservation of fruit extend from the more traditional, leaden pots for each fruit/flower (pots which are subsequently buried and isolated from the heat of the air, earthen pots 'well leaded within, and covered with earthen covers, well burnt and leaded likewise cementing or closing them together with the Goldsmiths wax or cement, consisting of stone pitch, rosen, powder of brick and such like') to glass bells which cover miniature silver trees where one can hang cherries for as long as 'two whole moneths' (Platt 1594, 2-4). The glass bells are submerged in a large pot of distilled water. $^{43}$ In addition to presenting various methods for storing fruits, Platt devotes much attention to the general issue of isolation and sealing:

These little pots you must place within greater, and these greater within vessels of wood, stopping up every breathing place that you can imagine (for here I can assure you that the ayr will be a player, unlesse you can keep it out of the Alley perforce. If you would afterwards bury these vessels, then were it requisite to pitch them well, both within and without (Platt 1594, 2). ${ }^{44}$

Although he discusses the use of earthen pots and vessels made of lead, Platt clearly prefers glass vessels as being 'the best of all others'. ${ }^{45} \mathrm{He}$ also offers a recipe on how to prepare and seal glass vessels, specially designed for the purpose of preserving fruit and flowers over the winter. He has his own recipe for the SigillumHermetis, which is quite different from Della Porta's:

Yet some commend the keeping of fruit or flowers in glasses made of purpose for them, to be the best of all others, so as the glasses be made with long necks, and be nipped (hermetice) with a pair of hot tongs, the manner whereof you shall find hereafter set down (Platt 1594, 2-3). ${ }^{46}$

Such sealed glasses are to be further isolated by immersing them into cold water. Other forms of sealing listed in the Floraes Paradise involve oiled paper, but also linseed oil boiled together with 'powder of amber' (Platt and Bellingham 1659, 149). One such recipe, moreover, records an interesting, and quite 'Baconian' query, that is, whether 'a Bladder will not serve instead of oily paper' (Platt and Bellingham 1659, 150). ${ }^{47}$

\footnotetext{
${ }^{43}$ Platt also offers a recipe for manufacturing a silver tree and a glass bell, and discusses distillation as a means of preventing water from putrefying.

${ }^{44}$ See also his recipe on '[h]ow to nip or close a glass with a pair of hot tongs, which is commonly called Sigillum Hermetis' (Platt 1594, 87).

${ }^{45}$ Platt claims that preserving fruits in glass bottles is to be preferred, particularly by comparison with more traditional recipes, which suggest the coating of fruits in 'wax well tempered with Turpentine, Pitch, Rosen, Sweet suet, or Barrows greace'. Such techniques are deemed useless for those fruits which 'begin to rot first at the core, as the Katherin pear, \& divers other sorts of fruit do' (Platt 1594, 2-3).

${ }^{46}$ The recipe for the Sigillum Hermetis, i.e., of how to seal a glass by melting its top with a pair of tongs, is given in Platt 1594, 87-88.

${ }^{47}$ The inflated pig bladder is one of Bacon's favorite instruments for the study of rarefaction and condensation. Trials for keeping flowers, fish or one's hand inside an inflated bladder are also recorded in the manuscript and published versions of the Sylva Sylvarum.
} 
Even more interesting than Platt's recipes and suggestions, however, is the way he deals with the question concerning the limits of such experiments. Unlike Della Porta, Platt does not claim to be able to keep fruits 'for a very long time' or 'for ever'. In fact, he is explicitly critical of such boasts, and claims that no matter how hermetical the sealing is, fruits will eventually begin to putrefy. The argument is partly empirical, partly theoretical:

But if the fruit begin to rot first at the core, as the Katherin pear, \& divers other sorts of fruit do, then all the outward covers and enclosures whatsoever (yea though they were dipped in dissolved Amber which is counted the purest and most defensative ferment of all the rest) will never be able to turn nature out of her bias. Here also sharp spirited wits have imagined that if spirit of wine wel rectified, were flutted with the imbibition of any flower, untill it could work no more upon the same, that thereby it were possible to preserve any flower of the same kind, along time therein. But this is to be understood onley of the dry leaves which bring nothing else but the tincture and strength of the hearb with them, and not of the moist leaves, which will leave a putrifying flame behind them, which in time will help to corrupt them (Platt 1594, 2-3).

From his observations in the field of gardening, Platt simply offers examples of fruits putrefying 'from the inside', thus providing evidence contrary to the accepted theory according to which putrefaction begins at the stalk. To this he adds an argument relating to his (alchemical) mattertheory: ${ }^{48}$ all bodies contain spirits of a more or less active nature, a 'putrifying flame' which will continue to work no matter how well sealed the closure is. In some cases, Platt claims, the enclosed spirits are particularly active: these are the so-called 'wild spirits', which 'can endure no imprisonment'. ${ }^{49}$ In other words, the study of putrefaction should take into consideration not only the properties and different characteristics of the air, but also the qualities of the spirits in bodies. Such spirits are, in Platt's view, 'unknown' to the 'vulgar', but a good knowledge of them is essential for the philosopher. ${ }^{50}$

Can bodies be preserved forever? Platt's answer is negative, and on this matter he is in perfect agreement with Bacon. This, however, does not make preservation devices less useful. It also does not make the theoretical question of preservation less interesting. Both Bacon and Platt are keen on knowing how putrefaction occurs and how to delay or speed up the process. Both are also interested in other phenomena related to putrefaction, such as concoction, induration and,

\footnotetext{
${ }^{48}$ On Platt's alchemical matter theory and its sources, see Thick 2010.

${ }^{49}$ Platt 1594, 87: 'For there can be certain wild spirits within who can endure no imprisonment, but if they can find no way, they will make way, bearing out before them both lock, bolt and hinges, and yet they are such as the Philosopher cannot want, though the vulgar sort know no use of them'.

${ }^{50}$ This is why Platt ends his recipe of the Sigillum Hermetis with a discussion concerning the type of spirit enclosed in bodies. 'Distilled oyl' or water can be kept for a long time in a sealed glass vessel. Meanwhile, 'the juyce of any strong or fiery plant, as also of any decoction that is apt to work it self into a body, as new must, or the strong wort wither of ale or beer, least you do not onely misspend your time your liquor, and break your glass, but also happen to get a shrewd turn your self if you be within gunshot. For there be certain wild spirits within who can endure no imprisonment, but if they can find no way, they will make way, bearing out before them both lock, bolt and hinges, and yet they are such as the Philosopher cannot want, though the vulgar sort know no use of them' (Platt 1594, 8788).
} 
most important of all, the restoration of spirits and the prolongation of life. Platt's books stand witness to a profound interest in improving preservation, securing restoration and delaying putrefaction. This is apparent in more traditional recipes devoted to means of preserving apples, grapes (Platt 1608, 81, 87, 93, 172), flowers, carrots and turnips (Platt 1608, 56-57), green walnuts (Platt 1594, 68), oranges, lemons or various juices, ${ }^{51}$ as well as to ways of rectifying wine and vinegar, or the spirit of wine. ${ }^{52}$ His interest is also apparent in the more esoteric recipes (or mere allusions to secret recipes) focused on how to make 'any decoction... to last longer', or how to make orange and lemon juice last from one year to the next. ${ }^{53}$ It is clear from such recipes that, instead of concentrating upon the isolation of the body, Platt suggests means of purifying and 'rectifying' it with the help of heat, cold, and distillation. He claims that the 'best way' to delay putrefaction requires 'a true and Philosophical rotation whereby the inward fire of nature may be stirred up in every vegetable, to defend itself sufficiently against all putrifying whatsoever' (Platt 1594, 81). ${ }^{54}$ Although Platt does not disclose particular restorative recipes in The Jewell House, he offers enough clues as to what particular substances might be tried in order to 'purify', 'restore' and 'revive' the vital spirits (i.e., substances which contain a large proportion of 'vegetative salt'). These include: niter, spirit of wine well rectified, quicksilver, plus a large list of other compound substances in which the art of the alchemist, doctor or gardener has concentrated the 'vegetative salt'. It is not surprising that Bacon's list of restoratives is very similar to Platt's. 55

What is perhaps most surprising, and has been little explored so far, is how both Bacon and Platt view the more traditional issue of preserving bodies and the study of putrefaction in close connection with other important natural processes, such as maturation, concoction and induration, on the one hand, and life restoration and prolongation, on the other. As a result, they record experiments dealing with the 'acceleration' of maturation in fruits and bottles of beer or cider, ${ }^{56}$ the 'clarification' of liquors (such as beer and wine), ${ }^{57}$ the restoration of stale beer by

\footnotetext{
${ }^{51}$ Platt is also advocating the use of sugar and sugared syrups to make preservatives. In this, he differs from Della Porta who is solely interested in the preservative powers of honey. See, for example, Platt 1594, 190-191.

${ }^{52}$ At the end of his posthumous Florae Paradise (1608) one can find 'An offer of some new, rare and profitable inventions', that is, a list of 'secrets' on offer (for sale), amongst which is how to make English wine, or how to produce cider which, through a process of maturation, will taste as claret or 'Rhenish wine' (Platt 1608, P3).

${ }_{53}$ Platt 1594, 181-182: 'And so I have kept both the juyce of cowslips which (if I be not deceived) will not last long by any ordinary course of preserving, and the juyce of Orenges simply of themselves without any addition, as sound and perfect at the years end, as they were the first day or rather (to speak truly) somewhat exalted in kind. But because such secrets are fitter for a Philosophers laboratory, then a getlewomans closet, I will not here offer that disgrace unto nature, to discover and magistery upon so base an occasion. And as concerning the keeping of Orenges and Limons in the same state, bigness, colour, \& taste, as they are brought us out of Spain, or Portugal, it may be that in my next labours I will write at large thereof, and in plain terms, according to those undoubted and approved trials which I have often made in mine own house for many years together'.

${ }^{54}$ See also Platt 1594, 187.

${ }^{55}$ Chief amongst these is the use of niter. For Platt on the use of niter for embalming, see Platt 1594, 101. Bacon extensively uses what he believes are the restorative powers of niter, and recommends it as an important agent in the prolongation of life. On the other hand, the manuscript of the Sylva Sylvarum records that 'Nitre maketh Bred and Flesh more short and [Nitre] more tender' (Rees 1981, 408).

${ }^{56}$ Platt's recipes for the acceleration/maturation of beer and his process of 'restoring' 'stale beer', as recorded at Platt 1594, 57ff., are almost identical with Bacon's similar experiments (310, 314, and 315) in the Sylva Sylvarum.
} 
burying it under the ground and mummification as belonging to the same category (Platt 1594, 57). They view such experiments as belonging to a more general exploration into the recesses and folds of nature, ${ }^{58}$ into the invisible motions of the active, living spirit entrapped inside of natural bodies. ${ }^{59}$ It is important to note that Platt and Bacon have different theories about the nature of this living spirit. Platt talks about 'vegetative salt', the quintessence and water capable of congealing the influences of celestial bodies, while Bacon's theory of spirits is both less alchemical and much more variegated (without being developed in full, it extends on a good number of pages in Bacon's more speculative writings). ${ }^{60}$ Of course, Platt's experiments are mostly focused upon producing useful or marvelous results: their relation with his corresponding alchemical theory of matter is rather loose, and he only makes connections occasionally and in passing. ${ }^{61}$ Where Platt and Bacon seem to agree, however, is in their way of looking at experiments with fruits as a privileged viewpoint to observe the hidden and invisible motions of the active spirits enclosed in bodies.

With respect to the specific case of Bacon, a series of questions present themselves. What was his aim in assembling large quantities of experiments with apples, plants and bottles of beer and in applying creative (and sometimes critical) readings and borrowings from various traditions? Did Bacon actually perform some of the experiments he describes? And if the answer is affirmative, what was his purpose? These are the questions to which I will now turn.

\section{Experimental Series: The Manuscript and the Printed Text of Sylva Sylvarum}

In this section I want to formulate a series of arguments, divided into three categories, to support my thesis that Bacon did in fact perform some of the experiments with fruit he recorded in his late natural histories and, particularly, in his posthumous Sylva Sylvarum.

In the first category, I would place Bacon's multiple recordings of experiments, as well as his lists of experiments, trials and queries, all relating to experiments with apples and other fruit.

\footnotetext{
${ }^{57}$ Platt has numerous experiments and recipes for the production and preservation of beer and cider. He also wrote a manifesto for the promotion of English wines, entitled An Offer of Some New, Rare and Profitable Inventions (1608). In it he alludes to his methods of speeding up fermentation and maturation with marvelous results, such as making cider very close in taste to 'Rhenish wines' (see Platt 1608, P3).

${ }^{58}$ Sometimes the language which Platt and Bacon use to talk about the purpose of their experimental research is strikingly similar. This is how the 'Epistle to the Reader' in Florae Paradise ends: 'And thus, gentle Reader, having acquainted thee with my long, costly, and laborious Collections, not written at adventure, or by any imaginary conceit in a Schollers private Studie, but wrung out of the earth, by the painfull hand of experience; and having also given thee a touch of Nature, whom no man as yet every durst send naked into the worlde, without the veyle; and expecting, by thy good encouragement for higher and deeper discoveries hereafter, I leave thee to the God of Nature, from whom all the true light of Nature proceedeth' (Platt 1608).

${ }^{59}$ They also seem to have quite similar view about how putrefaction can be turned into vivification by a 'controlled process'. As a result, they are both interested in fertilizers and fertilization and argue for the controlled use of niter, marl and dung. See Platt 1594 and Bacon 1857-1874, II, 525ff.

${ }^{60}$ On Bacon's matter theory, see Rees 1977; Rees 1996; Weeks 2007a; Weeks 2007b; Giglioni 2010.

${ }^{61}$ For Platt, experiments are not merely illustrations of his matter theory; rather, he often employs his matter theory as necessary background knowledge for devising or interpreting a given experiment.
} 
One reason behind his decision to record numerous variations of what in the end is the same basic experiment - that is, placing apples and other fruits under differing conditions 'to see what happens' - can be explained simply by the fact that Bacon did indeed perform them and recorded different results, formulated further questions and suggested further trials. A comparative study of the manuscript version and the published version of Sylva Sylvarum suggests a large number of such multiple recordings. Take, for example, the following list:

Put a green Apple into Hay, and leave another /of the same Apples to compare with it, and see / how much sooner the one will sweeten and ripen [before] <then> the other. / An Apple in a Boxe or chest. An Apple in quick Lime. / An Apple in Ashes. / An Apple in Lavender. / An Apple in Fennell. / An Apple in straws / An Apple closed up in yellow waxe / An Apple covered over with Apples or Crabbs. / An Apple covered over with Onions. / An Apple in Dung. / An Apple in the Aire. / An Apple in Chalke. / An Apple layd upon a vessel of Sacke or Malmesey. / An Apple hanged up in Smoke. / An Apple in Sand. / An Apple rouled gently with the Hand and layed up / An Apple in Wool / An Apple in Feathers / An Apple in Flower/ An Apple in Bran / L. Done Octob 10 (Rees 1981, 406).

What we have here is a list of 'traditional' preservatives relating to the apple experiments I have already discussed in the preceding sections. In the manuscript, this list is supplemented by other experiments, which record similar trials to be made in a conservatory of snow: 'Apples 4 <whereof> for sevenight 2. For a Moneth'. Similarly, '3 Apples' appear in the list of bodies to be buried 'in Earth', 'each in 3 several places'. Although most of the substances used here as preservatives as well as the technologies employed for preservation are well known, the multiple recordings of these experiments differ substantially from both the more classical recipes in the tradition of husbandry and from the instructions contained in Renaissance books of secrets. The published version does not merely expand on these lists, but develops several series of experiments dealing, respectively, with the comparative 'maturation' of apples kept in straw, hay, wax, crabs, and smoke (experiments 317-323), with the 'acceleration of maturation' of fruits pierced or bruised (what Bacon calls 'solution of continuity'), ${ }^{62}$ and with the beginnings of putrefaction. A comparative survey of the published and manuscript versions of such 'experiments' shows Bacon's selectivity: from the long list of preservatives enumerated in the manuscript, only a selection remains in the published version. For example, lavender, fennel and other plants are eliminated, while the attempt to roll an apple on a hard surface to see whether it matures earlier is recorded separately, in a different experiment. Other substances are added to the list, too, such as conservatories of snow, resin, plaster and quicksilver.

Moreover, and this belongs to the second category of arguments, even in the sketchy and schematic form of the manuscript, Bacon's lists provide a multitude of details absent from both Della Porta and Platt. An investigation into the types of details provided by the various forms of recordings, in the manuscript and in the published work, can be further divided into three subcategories: there are details referring to the experimental set-up, but there are also details

\footnotetext{
${ }^{62}$ This series appears in the Sylva sylvarum as 'experiments' 325, 326, 333, 858, 861.
} 
referring to the results of the experiments, as well as further methodological and theoretical instructions necessary for the replication of the same experiments.

Bacon's manuscript of the Sylva Sylvarum offers quite detailed descriptions of the experimental settings. We are given precise numbers for the series of trials, for the different places selected for 'burial', and for the number of apples subjected to the trial. Equally interesting is the date recorded at the end of various lists, meant to 'certify' the trial. Of course, such 'certification' should not be taken as a proof that the experiment was actually made on that particular date. It could be only a rhetorical element borrowed from the tradition of the books of secrets. ${ }^{63}$ Platt's Floraes Paradise contains the same kind of recording: the experiments often end with the standard phrase 'Probatum per...', followed by the name of Platt's source. ${ }^{64}$

By contrast, the published version of the Sylva does not record the date of the trial. Nor does it record the number of apples subject to the trial, or the number of repetitions of the same experiment. Instead, the published version offers a detailed description of the results of such trials. On the one hand, Bacon gives a quite thorough description of what happens to all these apples after a certain amount of time: how they look, how they taste and how they compare with each other. This detailed and accurate description of the results does not appear in any of the sources discussed in the previous section of my paper. Both Della Porta and Platt merely mention whether a recipe 'works' or not, or whether it is better than another recipe for preserving fruit. By contrast, the amount of detail offered by Bacon seems to be indicative of the fact that he has performed these experiments. This is particularly obvious when one reads various records of the same experiment across Bacon's natural histories. As we have already seen, keeping an apple in wax ends in two different recordings: in the Sylva Sylvarum it is recorded that 'after a month's space, the apple inclosed in wax was as green and fresh as at the first putting in, and the kernels continued white' (Bacon 1857-1874, II, 446), while in the De vijs mortis the record describes what happened to an apple kept longer under the same conditions until it begun to putrefy (Bacon 1996, 309). This variation in the 'lapse of time' plays an essential role in Bacon's experiments and is also a recurrent feature of the way some experiments are recorded. In the experiment describing the burial of lemons 'four foot within the earth' in a 'moist place and a rainy time', we are told that after a fortnight they 'come fourth no ways mouldy or rotten, but were become a little harder than they were; otherwise fresh in their colour; but their juice somewhat flatted', while, after another fortnight, they become putrefied (Bacon 1857-1874, II, 467. Emphasis added). ${ }^{65}$

\footnotetext{
${ }^{63}$ It can also have the value of an aide memoire (either to remember when a particular experiment or observation was made, or to remember an idea to be tried in the future). My thanks to Guido Giglioni for pointing this out to me. ${ }^{64}$ See, for example, 'Probatum per Maister Andr. Hill', or 'Probatum per Master Colborn' in experiments concerning grafting (Platt 1608, 135, 137, 149). Sometimes the sources are only identified by their initials. In some cases, the term probatum is missing, while in others the experiments end with a further query. Platt's sources can be gardeners, practitioners in glass-making and other mechanical arts, and even other authors writing about husbandry. On Platt's experts, see Mukherjee 2010; Thick 2010.

${ }^{65}$ The ways in which a lemon grows mold are described in other experiments throughout the Sylva Sylvarum. See, for example, Bacon 1857-1874, II, 453.
} 
This experiment records what Bacon calls a 'variation' in the mode of experimentation: by varying one of the parameters involved in the experiment (time), one can move from a particular question (How do burials contribute to the preservation of fruit?) to another (At what point does maturation transform itself into putrefaction?). It is a procedure frequently applied in Bacon's experiments, ${ }^{66}$ and represents a methodological innovation which allows for the extension of one experiment into a series of experiments simply by varying the original parameters. It is clear that all the experiments with fruit discussed so far belong to various series generated through the variation of two important parameters: the medium in which the fruit is placed and the amount of time the fruit is kept under certain conditions.

Such methodological additions and innovations represent the third category of arguments in favor of the claim that Bacon performed at least some of the experiments he discussed. In some cases, methodological additions are explicit, while in others a certain amount of conceptual and historical reconstruction is needed to access the methodology at the core of Bacon's experiments. For the purpose of this chapter, however, it suffices to point towards the most striking methodological innovation in his experiments with fruit: the introduction of a control group. In order to record the results of a series of experiments, Bacon assesses them comparatively with a group of fruits kept under 'regular' or 'normal' conditions. This control group is already present in some of the lists of experiments sketched out in the manuscript of the Sylva Sylvarum. ${ }^{67}$ The published version further develops these suggestions and refines them further. ${ }^{68}$ For example, the series of experiments investigating the effects of piercing and bruising upon the maturation of apples ends with a coda:

In these trials also, as was used in the first, set another of the same fruits by, to compare them; and try them, by their yellowness, and by their sweetness (Bacon 1857-1874, II, 448).

Note that Bacon does not only specify the need for a control group, but also indicates the parameters whose modification the experimenter should observe and record. This comparative evaluation of the results in each series of experiments is entirely missing from both the traditions of husbandry and natural magic. It is more sophisticated, remarkably precise and represents a unique and quite characteristic addition to Bacon's model of experimentation.

To sum up, I have formulated three main arguments in favor of the claim that Bacon did not merely select his experiments and examples from previous traditions, but performed some of the experiments himself. Both the multiple records he kept of various forms and variations of a traditional recipe, enriched with details and suggestions, and the 'extension' of an experiment into a cluster of related experimental settings by varying a precise number of parameters suggest

\footnotetext{
${ }^{66}$ See also Jalobeanu 2013.

${ }^{67}$ Rees 1981, 406: 'Put a green Apple into Hay, and leave another / of the same Apples to compare with it, and see / how much sooner the one will sweeten and ripen [before] <then> the other'.

${ }^{68}$ Among those experiments clearly stating the need for a control group are 317-322, 385 and 401 in Sylva Sylvarum.
} 
that Bacon in fact undertook repeated trials. The large number of details and the finesse of some of the recorded results also suggest repeated experimental practices and methodological reflections upon such practices. A further argument in favor of the claim that Bacon devoted substantial reflection to the methodological aspects of experimenting with fruits, moreover, is the presence of experiments dealing with the art of husbandry in the section dealing with the role of experimentation in the advancement of learning, added to De augmentis scientiarum (1623). A good number of the 'modes' relating to the art of experientia literata are exemplified with instances and experiments which stem from the tradition of husbandry.

\section{Laboratories for the Study of Spirits: Bacon's Apples and the Prolongation of Life}

We have seen so far that Bacon spent a lot of time reading and experimenting with fruit. His writings show a serious interest in reading, selecting, testing and developing experiments from the traditions of husbandry and natural magic. But what was the purpose of all this work? Why were these experiments so interesting to him? The best place to look if one wants an answer to this question is in his methodological writings where he investigated similar experiments. Experimenting with fruit appears to have been a continuing concern of Bacon for two reasons. On the one hand, selecting experiments from husbandry, natural history and natural magic in order to extend and 'translate' them into other fields was, according to Bacon, one of the keys to discovery ('invention'). As he boldly puts it in De augmentis scientiarum:

the best chance of bringing down as from heaven a showers of inventions at once useful and new, is to bring within the knowledge of one man, or a few who may sharpen one another by conference, the experiments of a number of mechanical arts; that by this translation (as I call it) of experiments the arts may mutually cherish and as it were kindle one another by mixture of rays. For though the rational method of inquiry by the Organon promises far greater things in the end, yet this sagacity proceeding by Learned Experience will in the meantime present mankind with a number of inventions which lie near at hand, and scatter them like the donatives that used to be thrown among the people (Bacon 1857-1874, IV, 417).

Examples include the translation of knowledge accumulated in the preservation of fruit in the tradition of husbandry into the (relatively) new art of making cider; by knowing that fruit matures better if it is kept for a while among other fruit of the same sort, the cider-maker keeps apples in piles on the ground before piercing and bruising them to foster putrefaction. Similarly, Bacon suggests that perhaps we might transfer what we have learned about the preservative powers of honey or about embalming into a different field, namely, the one pertaining to techniques of prolonging life (Bacon 1857-1874, IV, 417).

On the other hand, experiments with fruit are methodologically interesting not only because they exemplify the modalities of knowledge transfer through the art of experientia literata, but also because they shed light on the character and processes of nature. They belong to 
what Bacon calls the eighteenth kind of instances with special power (instantiae praerogativae), specifically termed 'Instances of the Pathway' (instantiae viae). These are special instances that 'chart the motions of nature as they gradually unfold' (Bacon 2004, 359). They cover particular natural processes which are invisible to the naked-eye observer because of their scale or because they unfold too slowly to be 'observable'. Among such processes Bacon lists vegetation, generation, putrefaction and vivification. The observation of such processes is compared to a night-watch: it is long and has many steps (hence the second name given to these instances: instantiae itinerantes and instantiae articulatae). It has several important phases of which, Bacon claims, the first is the most important. The careful study of the 'inception' of putrefaction, desiccation and vivification belongs to another category of instances of special power, namely 'Summonizing' or 'Evoking Instances'. Under them, Bacon lists experiments which are attempts to observe the first signs of the emission and departure of spirits detained in bodies. Both sets of instances belong to the more general category of 'Instances of the Lamp', that is, special experiments and shortcuts designed to 'show' and to 'make visible' the invisible actions of the spirit.

In conclusion, experiments with fruit belong to a more general research plan which attempts to survey the particular motions of the spirit, at work within a body (generation, growth and maturation) while struggling to leave that body (putrefaction and desiccation). Fruits are particularly apt laboratories for surveying such motions: they were once part of a living being, and although cut off, one can presume that they still contain some of the living spirit present throughout the plant. The presence of this living spirit would explain, for Bacon, a process such as maturation (i.e., the natural working of the spirit in a fruit until this is fully grown). The attempt to survey the 'inception of putrefaction' (i.e., the initial moments when the spirit begins to depart from rotten apples) would give the experimenter a way to classify natural processes. It is clear from Bacon's theory that natural processes such as vegetation, concoction (leading to growth), maturation and putrefaction are mere names attached to what is in fact one seamless continuum of life. A fine line has therefore to be drawn between maturation and putrefaction, and it is the role of experiments to do so.

On the other hand, isolating fruit under various conditions is also a way of manipulating the spirit enclosed in it. Hermetic seals, for example, prevent the natural flight of the spirit (and the visible effect is the desiccation or putrefaction of the body), but cannot stop its motions. Depending on the type of isolating substance and the time, such an experiment can force the spirit to 'eat' the body in which it is enclosed. Or, to use Bacon's words in Historia vitae et mortis,

when spirit is well restrained, instead of elaborating or turning thin matter into spirit (which the spirit does when it is given an escape route) it converts gross matter into moist, with the result that things are softened and have, so to speak, new life put into them (Bacon 1996, 319). 
Bacon claims that this is precisely why hermetic seals do not work as technologies of conservation; apples coated in wax or sealed in amber will eventually be turned into 'moisture' by the spirit working within. By contrast, porous closures or substances which absorb moisture act as better preservatives. It is therefore better to keep apples in such materials as flour, bran and sand. This, however, is a minor side issue when compared with other, more theoretical implications underlying such experiments. Sealed closures, for instance, can be used as instruments and technological devices to study the workings of a spirit in a controlled manner, in isolation from those agents external to it. Sealing is one way to 'arm' and 'defend' a body against 'any external force', to stop 'extraneous and extrinsic motions', and hence to discover the motions 'working within' (Bacon 2004, 435). This is a particularly good way to study what Bacon calls 'dissimilar and various schematisms (like putrefaction) which bodies gain with the passage of time'. But this technology can also produce new effects, for the 'imprisonment' of a body can inhibit 'spontaneous motion', or can produce a violent motion of response (Bacon 2004, 435).

Furthermore, experiments with fruit belong to a more comprehensive investigation into what Bacon calls the 'ways of death', that is, the ways spirits 'multiply', destroy and 'wreck the very workshop by which it is itself repaired' (Bacon 1996, 275). The De vijs mortis delineates a theoretical method and an experimental methodology for the study of such phenomena. The theory itself is complex and sometimes confusing and contradictory (since the writing was never finished and bears the traces of continuous rewriting). ${ }^{69}$ The methodology outlined therein is, by contrast, quite clear. It amounts to study first how inanimate beings putrefy in order to extend these results to animate beings:

In the first place... anyone who tries to examine the deterioration of an animal, and investigate its causes and cures (if any there be) or the means at least of delaying it, ought to start by looking at the animal first as an inanimate thing which does not take on food, and only then separately as an animate thing which does. For it is certainly true that whatever a natural inanimate body (like wood, stone, metal, uprooted plant, and so forth) suffers from time or age, the surrounding air, the rays of the heavenly bodies, and the changes and vicissitudes of the climate, the same things are also endured by the living body, except that the vital nature superadded can partly repel the injuries inflicted by time and external factors, and partly (which is the main thing) repair and make food these same injuries by taking on food (Bacon 1996, 275).

The study of 'uprooted plants' - or apples, for that matter - becomes, therefore, a prerequisite to the study of maturation, aging and decay of more complicated living beings, such as animals (and perhaps also humans). In conclusion, Bacon's apples can be viewed as simplified and selfcontained laboratories for the study of the basic motions of the spirits enclosed in matter. Bacon seemed to have believed that it was possible to transfer the results obtained in his 'apple

\footnotetext{
${ }^{69}$ For the various strata of De vijs mortis and the composition of the manuscript, see Rees's 'Introduction' to Bacon 1996.
} 
laboratories' to the more complex bodies of animals by simply adding parameters into his experimental set-ups (for example, by taking into consideration the fact that animals must consume food).

\section{Conclusion}

The main purpose of this paper was to demonstrate how the investigation of a particular series of experiments, recurrent in Bacon's writings, can shed much needed light on two related (and major) problems in the field of Baconian studies, that is, Bacon's use of natural-historical sources and the defining characteristics of his experimental strategies. I have shown the extent to which Bacon selected, developed and criticized recipes, trials and experiments collected from available works of natural history, husbandry and natural magic. I have then argued that Bacon developed this primary material further and that he devised experiments whose results were subject to multiple and careful recordings, in both his unpublished and published writings. Finally, I have explained the way in which experiments involving apples were integrated into Bacon's larger programme to study the hidden motions and appetites of spirits. In picking apples as objects of study Bacon was quite traditional; in developing technologies of conservation and recipes for the prolongation of life on the basis of his study of apples, he was again following in the footsteps of his predecessors, such as Giambattista Della Porta and Hugh Platt. However, in devising an experimental methodology which would allow him to use apples as laboratories for the study of the hidden motions of spirits, he went beyond the achievements of his predecessors. In further elaborating methodological strategies to transfer knowledge accumulated in experiments with fruit into the more complex 'laboratory' of the animal body, Bacon opened avenues unknown to his contemporaries. Living behind the closed waters of the mechanical arts, he emerged into the vast sea of experimental philosophy.

\section{References}

Bacon, Francis. 1857-1874. Works, eds. J. Spedding, R. L. Ellis and D. D. Heath, 14 vols. London: Longman.

Bacon, Francis. 1996. Philosophical studies, c. 1611-c. 1619. Ed. G. Rees, Vol. VI, The Oxford Francis Bacon. Oxford: Clarendon Press.

Bacon, Francis. 2004. The Instauratio magna. Part 2, Novum organum and associated texts. Ed. G. Rees and M. Wakely. Vol. XI, The Oxford Francis Bacon. Oxford: Clarendon Press.

Bacon, Francis. 2007. The Instauratio magna. Part 3, Historia naturalis et experimentalis : Historia ventorum and Historia vitce \& mortis. Ed. G. Rees. Vol. XII, The Oxford Francis Bacon. Oxford ; New York: Oxford University Press.

Bacon, Francis. 2013. Early Writings, 1584-1596, eds. A. Stewart and H. Knight. Vol I, The Oxford Francis Bacon, Oxford: Clarendon Press. 
Balbiani, Laura. 2001. La Magia Naturalis di Giovan Battista Della Porta. Lingua, cultura e scienza in Europa all'inizio dell'eta moderna. Bern: Peter Lang.

Borelli, Arianna. 2014. Thinking with optical objects: Glass spheres, lenses and refraction in Giovan Battista Della Porta's optical writings. Journal of Early Modern Studies 3: 39-62.

Bushnell, Rebecca W. 2003. Green desire : imagining early modern English gardens. Ithaca, N.Y. ; London: Cornell University Press.

Columella, Lucius Junius Moderatus. 1745. Of Husbandry, in Twelve Books: and his book, concerning Trees. Translated into English, with illustrations from Pliny, Cato, Varro, Palladius and other ancient and modern authors. London: A. Millar.

Eamon, William. 1985. Science and Popular Culture in Early Modern Italy: The 'Professors of Secrets' and Their Books. The Sixteenth Century Journal 16:471-485.

Eamon, William. 1994. Science and the Secrets of Nature: Books of Secrets in Medieval and Early Modern Culture Princeton: Princeton University Press.

Eamon, William, and F. Paheau. 1984. Accademia Segreta of Girolamo Ruscelli: A Sixteenth Century Italian Scientific Society. ISIS 75:327-342.

Estienne, Charles, and Iean Liebault. 1570. L'Agriculture et maison rustique. Paris: Jaques Du Puys.

Estienne, Charles, and Richard Surflet. 1600. Maison Rustique, or the Countrie Farme, London: Bonham Norton.

Fussell, G. E. 1969. The Classical Tradition in West European Farming: The Sixteenth Century. The Economic History Review 22: 538-551.

Giglioni, Guido. 2010. Mastering the Appetites of matter: Francis Bacon's Sylva Sylvarum. In The Body as Object and Instrument of Knowledge: Embodied Empiricism in Early Modern Science, edited by C.T. Wolfe and Ofer Gal, 149-167. Dordrecht: Springer.

Giglioni, Guido. 2012. Philosophy According to Tacitus: Francis Bacon and the Inquiry into the Limits of Human Self-Delusion. Perspectives on Science 20:159-182.

Harkness, Deborah. 2007. The Jewell House: Elizabethan London and the Scientific Revolution. Yale: Yale University Press.

Jalobeanu, Dana. 2008. Bacon's Brotherhood and its classical sources. In Philosophies of technology: Francis Bacon and his contemporaries, eds. C. Zittel, G. Engel, R. Nanni and N. C. Karafyllis, 197-231. Leiden: Brill.

Jalobeanu, Dana. 2012. Francis Bacon's Natural History and the Senecan Natural Histories of Early Modern Europe. Early Science and Medicine 17:197-229.

Jalobeanu, Dana. 2013. Learning from Experiment: Classification, Concept Formation and Modeling in Francis Bacon's Experimental Philosophy. Revue Roumaine de Philosophie 57:75-93.

Jalobeanu, Dana, and Cesare Pastorino. 2014. Introduction. In Instruments and Arts of Inquiry in Early Modern Europe, special issue of Journal of Early Modern Studies, eds. D. Jalobeanu and C. Pastorino. Bucharest: Zeta Books.

Mukherjee, Ayesha. 2010. Floras Paradise: Hugh Platt and the Economy of Early Modern Gardening. The Seventeenth Century 25:1-26.

Kiernan, Michael. 2012. Introduction. In The Historie of the Raigne of King Henry the Seventh and other works of the 1620s, edited by Michael Kiernan, xxi-lxxxix. Oxford: Clarendon Press.

Orsi, Laura. 2005. Giovan Battista della Porta's Villa (1592) between tradition, reality and fiction. Anali di Storia moderna e contemporanea 11:11-66. 
Porta, Giambattista della. 1591. Magia naturalis libri vingti. Francoforti: Andreae Wecheli.

Porta, Giambattista della. 1658. Natural Magick in Twenty Books. London: Thomas Young and Samuel Speed.

Platt, Hugh. 1594. The Jewell House of Art and Nature, conteining divers rare and profitable inventions, togther with sundry new experimentes in the art of husbandry, distillation and moulding. London: Peter Short.

Platt, Hugh. 1608. Floraes Paradise, beautified ... with sundry sorts of delicate fruites and flowers. London: Printed by H. L. for W. Leake.

Platt, Hugh Sir, and Charles Bellingham. 1659. The garden of Eden.. London: printed for William Leake.

Pliny, the Elder. 1601. The Historie of the World, commonly called the Naturall Historie of $C$. linius Secundus. Translated by Philemon Holland. London: A. Islip.

Pliny, the Elder. 1949- 1962. Natural history. In The Loeb classical library, edited by H. Rackham and W. H. S. Jones. Cambridge,: Harvard University Press.

Rees, Graham. 1981. An Unpublished Manuscript by Francis Bacon: Sylva Sylvarum Drafts and Other Working Notes. Annals of Science no. 38:377-412.

Rusu, Doina-Cristina. 2013. From Natural History to Natural Magic: Francis Bacon's Sylva Sylvarum, PhD dissertation, Radboud University, Nijmegen.

Stewart, Alan, and Harriet Knight. 2013. Introduction. In Early Writings, 1584-1596, eds. A. Stewart and H. Knight. Vol I, The Oxford Francis Bacon, Oxford: Clarendon Press.

Thick, Malcolm. 2010. Sir Hugh Plat : the search for useful knowledge in early-modern London. Totnes: Prospect.

Vine, Angus. 2008. Francis Bacon's Composition Books. Transactions of the Cambridge Bibliographical Society:1-31.

Vine, Angus. 2011. Francis Bacon, the Waste-book, and the Ledger, English Manuscript Studies 1100-1700. English Manuscript Studies 1100-1700 16:197-218.

Yeo, Richard. 2014. Notebooks, English Virtuosi, and Early Modern Science: University of Chicago Press.

Weeks, Sophie. 2007a. Francis Bacon's Science of Magic, PhD Dissertation, University of Leeds.

Weeks, Sophie. 2007b. Francis Bacon and the Art-Nature Distinction. Ambix no. 54 (101-129). 